\section{Clinicians call for ban on sales of energy drinks to children}

\section{By Adrian O'Dowd}

$\mathrm{P}$ ressure on the government to ban the sale of caffeinated energy drinks to children and young people to tackle obesity (and related bad oral health) as well as mental health problems, is growing as part on an ongoing consultation.

In August, the Department of Health \& Social Care launched a consultation ${ }^{1}$ as part of its childhood obesity plan, ${ }^{2}$ seeking views on whether the law should be changed to prevent children from buying energy drinks that contain more than $150 \mathrm{mg}$ of caffeine per litre.

One $250 \mathrm{ml}$ can of energy drink contains around $80 \mathrm{mg}$ of caffeine - the equivalent of nearly three cans of cola. Some energy drinks also contain exceptionally high levels of sugar on average, they have $60 \%$ more calories and $65 \%$ more sugar than other regular soft drinks.

Campaigning group Action on Sugar has said that with more than two thirds of 10-17-year-olds and a quarter of 6-9-yearolds consuming energy drinks, they were likely to be contributing to both obesity and tooth decay in children.

The BDA supports a ban and its Chair Mick Armstrong said: 'These drinks are habit forming, highly acidic and can come laced with 20 teaspoons of sugar - far more than a can of coke.

'Tooth decay remains the number one reason for hospital admissions among children and young people. Ministers like to talk about prevention. They can prove it by calling time on the marketing and sale of energy drinks to kids.

Professor Russell Viner, President of the Royal College of Paediatrics and Child Health, wrote an editorial ${ }^{3}$ in The BMJ published on 20 September 2018 in which he argued that children and young people in high income countries were consuming more sugar and calories than required and were therefore unlikely to need additional energy.

This combined with regular caffeine consumption was concerning, explained Viner, because there was little evidence of the effect caffeine could potentially have on the developing body.

In a 2014 survey $^{4}$ of more than 5,000 children in England, 14\% of 11-15-year-olds reported consuming energy drinks at least two to four times a week, and $5 \%$ of all young people reported drinking energy drinks daily.

Viner wrote of the high sugar content in many of these drinks (as much as $27 \mathrm{~g}$ of sugar per $250 \mathrm{ml}$ serving): 'This undoubtedly contributes to the overall calorie excess and resultant obesity epidemic among our children.

In The BMJ editorial, Viner said that caffeine was probably the most commonly used psychoactive drug across the world because it increased activity and heightened attention and awareness, but it also increased anxiety, reduced sleep and was linked with behavioural problems in children.

Despite this, little was known about the safety profile of caffeine. Energy drinks can contain at least $320 \mathrm{mg} / \mathrm{L}$ of caffeine.

This was alarming, said Viner, because psychological distress could lead to risky behaviours like drug use and poorer academic attainment.

Many UK supermarkets had now banned the sale of caffeinated energy drinks to under 16s, and several countries had bans in place, he acknowledged, and the Royal College of Paediatrics and Child Health supported these restrictions, alongside an evaluation of the effect that these policies had on young people's purchasing habits, and their health.

'I believe there is now sufficient evidence to act to protect children', said Viner. 'When the twin epidemics of obesity and mental health problems stalk the land, we cannot afford to allow marketing to drive consumption of new products likely to worsen obesity and the wellbeing of our children.
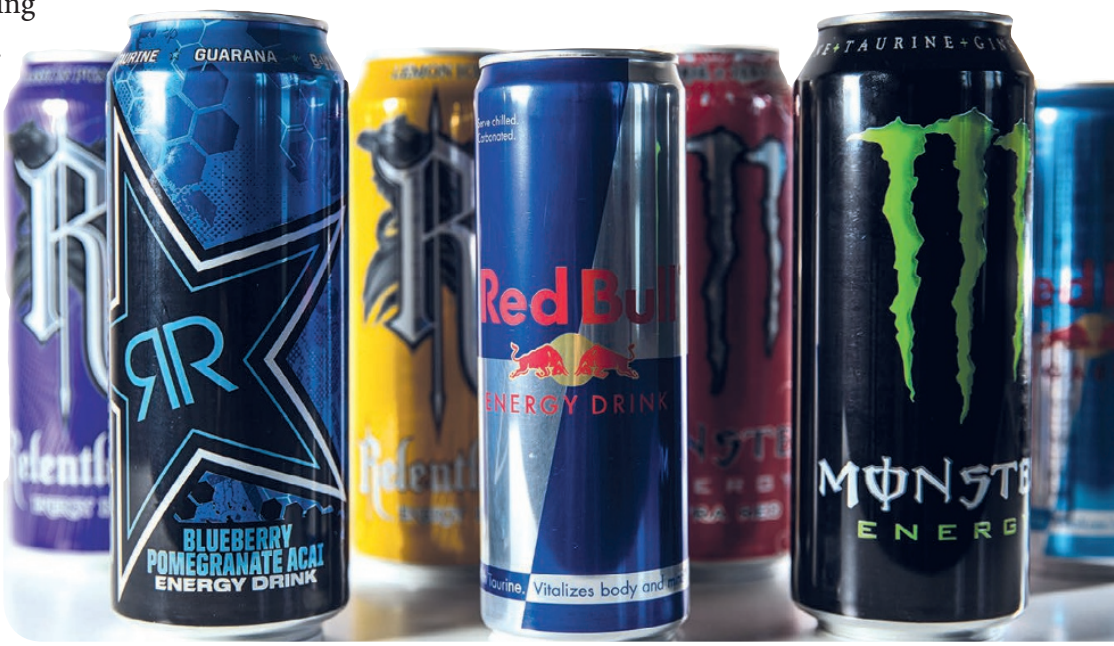

Dr Kara Gray-Burrows, Lecturer in Dental Public Health at the School of Dentistry, University of Leeds, is also supportive of a change in the law, saying: 'Essentially, I agree that the sale of energy drinks to children should be banned. Energy drinks contain large amounts of sugar and caffeine, which many would argue adults should avoid consuming, therefore it is even more imperative that children should not be consuming such drinks.

'However, it is always important to consider that although these upstream interventions are more likely to have a greater impact on behaviour, they are not always acceptable to the general population; therefore gaining grassroots support for such action will be equally important.'

The government's consultation closes on 21 November 2018.

1. Department of Health \& Social Care. Sale of energy drinks to children: Consultation (30 August 2018). Available at https://consultations.dh.gov.uk/obesity/sale-of-energy-drinksto-children/ (accessed 17 September 2018).

2. Department of Health \& Social Care. Childhood obesity: a plan for action, chapter 2. Available at https://www.gov.uk/government/publications/childhood-obesity-a-plan-foraction-chapter-2 (accessed 17 September 2018).

3. Viner R. Editorial: Ban on sale of energy drinks to children. BMJ 2018; 362: k3856. DOI: 10.1136/bmj.k3856. Available at http://www.bmj.com/content/362/bmj.k3856 (accessed 3 October $\left.201^{*}\right)$.

4. Brooks F, Magnusson J, Klemera E, et al. HBSC England national report 2014. University of Hertfordshire, 2015. Available at https://www.researchgate.net/publication/282857118_ HBSC_England_National_report (accessed 17 September 2018). 